\title{
Proteomic-Based Approaches for the Study of Ischemic Stroke
}

\author{
Haiying $\mathrm{Li}^{1} \cdot$ Wanchun You ${ }^{1} \cdot$ Xiang $\mathrm{Li}^{1} \cdot$ Haitao Shen ${ }^{1} \cdot$ Gang Chen ${ }^{1}$ (D) \\ Received: 25 June 2019 /Revised: 25 June 2019 / Accepted: 27 June 2019/Published online: 5 July 2019 \\ (C) Springer Science+Business Media, LLC, part of Springer Nature 2019
}

Ischemic stroke is the most common type of stroke. Despite the fact that there have been extensive efforts for establishing accurate diagnose and efficient therapy, ischemic stroke continues to be one of the main causes of death worldwide $[1,2]$. Currently, genomics provides information about what the body "can do," transcriptomics provides information about what the cell "will do," while proteomics tells us "what is happening." Proteomics complements genomics and transcriptomics and provides information about the implementation of proteins as the main functional mediators of cells, such as their post-translational modification and their interactions with other biological molecules [3]. In the last years, studies focusing on genomics and transcriptomics aimed to discover new diagnostic or prognostic evidence for ischemic stroke [4]. However, the state of brain cells after ischemic stroke is most directly related to protein function, which is also the target of most drug intervention. Therefore, investigations at the protein level are favorable for the in-depth description of neuronal injury after ischemic stroke. Innovative high-throughput proteomics techniques can help us accurately evaluate the degree of neuronal injury after ischemia, study the mechanism of drug action, and explore the role of key proteins in neuronal injury. Using these emerging proteomics techniques, diagnostic and prognostic biomarkers for ischemic stroke may be identified. For years, mass spectrometry (MS)-based proteomics has enabled us to obtain large profiling datasets with very high precision. Here, the recent advances in proteomic researches in ischemic stroke are outlined.

Haiying Li and Wanchun You contributed equally to this work.

Gang Chen

nju_neurosurgery@163.com

1 Department of Neurosurgery \& Brain and Nerve Research Laboratory, The First Affiliated Hospital of Soochow University, 188 Shizi Street, Suzhou 215006, Jiangsu Province, China

\section{Studies Performed in Human Brain Tissue/Cerebrospinal Fluid/Plasma}

Aiming at identifying potential biomarkers of ischemia, twodimensional gel electrophoresis (2DE) and MS were employed to analyze the differences between post-mortem cerebrospinal fluid samples and cerebrospinal fluid from healthy subjects [5]. H-FABP was identified as a potential biomarker for ischemic stroke. Compared with plasma samples healthy controls $(n=21)$, the differential expression of apolipoprotein CI, apolipoprotein CIII, serum amyloid A, and antithrombin-III fragment were detected by onedimensional electrophoresis coupled MS [6]. Using enzymelinked immunosorbent assay (ELISA), apolipoprotein CI and apolipoprotein CIII were further considered to be as potential plasmatic markers to distinguish between ischemic and hemorrhagic stroke. Proteomic analysis by 2DE-MALDI-TOF/ TOF MS was performed to reveal differential protein expression in endothelial progenitor cells between healthy subjects $(n=11)$ and ischemic stroke patients $(n=11)$. Two of the differentially expressed proteins, endoplasmatic reticulum protein-29 and CdC-42, were only expressed in endothelial progenitor cells from healthy subjects, whereas elongation factor- 2 was only identified in endothelial progenitor cells from ischemic stroke patients. Furthermore, peroxiredoxin-1 expression was identified to be $10 \times$ stronger in ischemic stroke patients than in healthy subjects [7]. Microdialysates from infarct core, penumbra, and the unaffected contralateral brain regions of patients suffering an ischemic stroke $(n=6)$ were analyzed by TMT. Compared with the contralateral samples, a total of 53 proteins showed an increasing trend in the infarct core or penumbra. Among these, the increase of glutathione S-transferase $\mathrm{P}$, peroxiredoxin-1, and protein S100-B in the blood of stroke $(n=14)$ patients were further validated with ELISA [8].

Datta et al. studied the commonly regulated infarct proteome from three different brain regions (putamen, thalamus, and the parietal lobe) of female Japanese patients by an 8plex iTRAQ-based 2D-LC-MS/MS strategy [9]. Among the identified 1520 proteins, energy metabolism-related proteins 
(SLC25A11, SLC25A12, GOT2, and MDH2) were downregulated, while proteins related to reactive gliosis (VIM, GFAP), anti-inflammatory response (ANXA1, ANXA2), and iron metabolism-related proteins (FTL, FTH1) showed an increasing trend. The deregulated proteins could be useful as potential therapeutic targets or biomarkers for ischemic stroke. Using 2DE-MALDI-TOF/TOF MS, García et al. compared the protein profiles between tissue samples from ischemic ipsilateral (infarct core and peri-infarct area) and healthy contralateral hemispheres of 3 ischemic stroke patients obtained within the first $6 \mathrm{~h}$ after death [10]. Among the identified 51 proteins, 8 candidates including GELS, CYTA, CNTN1, CYBP, SEPT5, PYGB, GDIR1, and DRP2 were selected from different functional categories based on their potential scientific relevance. From the 8 candidates, GDIR1, DRP2, and CNTN1 were altered in patient serum samples, which may well serve as biomarkers for long-term stroke prognosis. Utilizing MS-based proteomics, ceruloplasmin, complement component $\mathrm{C} 8$ gamma, and platelet basic protein have been shown to be significantly different between the ischemic patients $(n=35)$ and the controls $(n=12)$ [11]. And, platelet basic protein was further identified as a candidate serum biomarker for a transient ischemic attack. A quantitative proteomic analysis of serum from both acute ischemic stroke patients and control subjects by the iTRAQ-Based LC-MS approach revealed 389 high confidence protein identifications [12]. Among 60 proteins showing $>1.5$-fold change, vWF, ADAMTS13, S100A7, and DLG4 were further investigated in serum by ELISA. Nguyen et al. examined the serum proteome of stroke patients $(n=44)$ by utilizing label-free relative quantification and correlated these with the depression rating scale scores at 3 months post-stroke [13]. The results indicated that downregulation of complement expression in the periphery in conjunction with increasing MADRS scores post-stroke may be a biomarker for incomplete recovery of brain metabolic needs, homeostasis, and inflammation following ischemic stroke damage.

Promising biomarker candidates have been investigated in several studies involving animal models, followed by validation in human body fluids. By DiART-Label proteomic analysis of ischemic mouse brain, Song et al. identified clusterin as a potential biomarker for severity of an acute ischemic stroke, which was validated in human serum [14]. As a result of LCMS/MS analysis, a total of 1600 proteins were identified in the thrombus derived from four acute ischemic stroke patients. Among the identified proteins, 341 proteins are commonly detected in all the four patients included in this study [15]. To verify proteomic biomarkers for minor stroke and transient ischemic attack from a list of 141 candidate proteins, Penn et al. applied the multiple reaction monitoring-mass spectrometry (MRM-MS) in plasma samples from 545 participants [16]. Among the 141 candidate proteins, 9 proteins including L-selectin, insulin-like growth factor-binding protein 3, hyaluronan-binding protein 2 , coagulation factor $\mathrm{X}$, serum paraoxonase/lactonase 3 , thrombospondin-1, heparin cofactor 2, apolipoprotein B-100, and von Willebrand factor were significant univariate predictors of a transient ischemic attack. Based on label-free spectral counting, 30 differentially expressed proteins between infarcted and contralateral areas were identified. Among them, SAHH2 was subsequently verified in the plasma of ischemic stroke patients and considered meaningful as a prognostic biomarker of neurological improvement [17].

\section{Tissue Proteomics Studies in Animal Ischemia Model Without Intervention}

Using 2DE analysis and MALDI-TOF MS, there were four studies performed in rats to tested the different protein expression in ischemic cortex between middle cerebral artery occlusion (MCAO) group and sham group at $24 \mathrm{~h}$ after surgery [18, 19], a 30-min ischemia group and 2-h ischemia group [20], and a nondiabetic group and diabetic group [21]. Compared with sham group, upregulation of $60 \mathrm{kDa}$ heat shock protein, dehydropyrimidinase-related protein 2 , t-complex protein 1 , Rho GDP dissociation inhibitor, spectrin alpha II chain, heat shock cognate protein 70 pseudogene 1, and tropomodulin 2 after focal cerebral ischemia in rats was proved [18, 19]. The 2-h ischemia group indicated near complete loss of ATP production, synaptic dysfunction with degraded cytoarchitecture, more conservative chaperone activity, and additional cell survival factors than those seen in the 30-min ischemia group [20]. Compared with nondiabetic MCAO rats, expression of metabolism-related enzymes, including isocitrate dehydrogenase, glyceraldehyde-3-phosphate dehydrogenase, adenosylhomocysteinase, pyruvate kinase, and glucose-6phosphate isomerase was decreased in diabetic MCAO rats, suggesting that the diabetic condition may enhance brain ischemic damage via downregulating metabolism-related protein expression [21]. In addition, the 2DE-coupled MALDITOF MS was used to test ischemia-induced changes in protein level in the pituitary, adrenal gland, splenic lymphocytes, hippocampus, plasma, spinal cord, and sciatic nerve [22-25]. Based on label-free quantitation, TDP43, FUS, hnRNPA1, PSF/SFPQ, and p54/NONO were found to be aggregated in ipsilateral neocortical tissue following ischemia/reperfusion [26]. Furthermore, iTRAQ-MALDI-MS/MS was employed for the discovery of changes in protein associated with ischemia in the penumbra, ventricular zone, and serum [27-29]. Law et al. found that inflammation and neurogenesisrelevant proteins were dysregulated in the penumbra of the Macaca fascicularis stroke model [28]. Similarly, Gunton et al. found that inflammatory mediators, such as antiproteases and cytokine/growth factor-binding proteins, were upregulated in the ventricular zone after cortical stroke in mice [27]. 
And, upregulation of RHOA and CDC42 in the penumbra was proved in a rat ischemic model, which may serve as a potential serum biomarker [29].

\section{Tissue Proteomics Studies in Animal Ischemia Model with Intervention}

First, 2-DE combined with MALDI-TOF analysis was performed to identify proteomic changes in the penumbra and cortex induced by preconditioning and hypothermia in the murine MCAO model [30-33]. The expression of HSP70, HSP27, HSP90, guanylyl cyclase, muskelin, plateletactivating factor receptor, and beta-actin was increased in the ipsilateral cortex at $24 \mathrm{~h}$ after preconditioning induced by a 10 -min transient MCAO [30]. And, both cPKC $\beta$ II-interacting proteins and $\mathrm{nPKC} \varepsilon$-interacting proteins were found to be involved in hypoxic preconditioning-induced neuroprotection against cerebral ischemia in mice [31,32]. Pharmacological preconditioning using the immune activator D192935 induced a proteomic signature following cerebral ischemia that is associated with neuroprotection in the rhesus macaque [34]. Hypothermia was typically associated with opposite protein expression changes in the penumbra (cortex) to those induced by stroke under normothermic conditions but not in the core (striatum) in a rat ischemic model induced by endothelin-1 [33].

Proteomics analysis was performed to understand the mechanisms underlying the repair function of adiposederived mesenchymal stem cell administration and human cerebral endothelial cell (hCMEC/D3) transplantation in experimental ischemia models. A total of 2416 proteins in adipose-derived mesenchymal stem cell secretome were identified [35], while mitochondrial dysfunction (paraplegin matrix AAA peptidase subunit, SPG7), neuroinflammation (peroxiredoxin 6, PRDX6), and neuronal death (zinc finger protein 90, ZFP90) were markedly reduced in the hCMEC/ D3 treatment group compared with the control group [36].

Ferulic acid exerts a neuroprotective effect in cerebral ischemia through its anti-oxidant and anti-inflammation activity. Koh et al. conducted a series of proteomics experiments by 2DE combined with MALDI-TOF analysis to analyze the changes in proteomics caused by ferulic acid [37-40]. The results showed that ferulic acid attenuated ischemia-induced decrease of adenosylhomocysteinase, isocitrate dehydrogenase $[\mathrm{NAD}(+)]$, mitogen-activated protein kinase kinase 1 , glyceraldehyde-3-phosphate dehydrogenase, protein phosphatase $2 \mathrm{~A}$ subunit $\mathrm{B}$, hippocalcin, peroxiredoxin-2 and thioredoxin, and increase of pyridoxal phosphate phosphatase and heat shock protein 60 in rat MCAO model.

In addition, proteomics analysis has been used to light on the mechanisms underlying pleiotropic actions of rt-PA [41] and the neuroprotection of traditional Chinese medicines (baicalin [42], Ginkgo biloba extract (EGb761) [43], curcumin [44], Danhong injection [45], quercetin [46], rhubarb [47], hydroxysafflor yellow A [48], Xiao-Xu-Ming decoction [49]), asialoEPO [50], melatonin [51], estradiol [52], PACAP38 [53], tetrandrine [54], simvastatin [55], resveratrol [56], PPAR $\alpha$ agonist [57], tetramethylpyrazine nitrone [58], and grape seed extract [59] against ischemic injury).

\section{Studies in Cell Lines Further Verified in In vivo Ischemia Model}

Using 2-DE analysis and MALDI-TOF MS, nucleoside diphosphate kinase $\mathrm{A}$ has been identified to be upregulated in primary cortical neuronal cultures exposed to oxygen-glucose deprivation (OGD) [60]. And then, the authors verified a neuroprotective role of nucleoside diphosphate kinase A against ischemia-related injury in cultured neurons by using RNAi and an adenoviral vector-induced overexpress. Based on stable isotope labeling with amino acids (SILAC) followed by LC-MS/MS analysis, 19 proteins were found differentially secreted between OGD and normoxia/normoglycemia conditions in cultured hCMEC/D3 [61]. Western blot was used and further verified a set of 9 differentially secreted proteins. Among them, COL1A2, CLU, IGFBP2, ANXA1, and PRDX3 were analyzed in serum samples of ischemic stroke patients $(n=38)$, stroke-mimicking conditions $(n=18)$, and healthy controls $(n=18)$, which suggested a potential of IGFBP2 for the diagnosis of cerebral ischemia. Based on existing reports and author's findings that hypoxicconditioned medium derived from bone marrow mesenchymal stromal cells protects against ischemic stroke in rats, cytokine antibody arrays and label-free quantitative proteomics analysis were used to analyze the differences between hypoxic-conditioned medium and normoxic-conditioned medium from bone marrow mesenchymal stromal cells. A total of 163 proteins were differentially expressed between the two groups, including 107 upregulated proteins and 56 downregulated proteins [62].

\section{Challenges and Shortcomings}

Although proteomics studies have contributed with a long list of potential biomarkers for diagnosis, prognosis, and monitoring of ischemic stroke, most of them have not been implemented in clinical application successfully. When reviewing the existing reports, shortcomings, including small sample size; ignoring cell types [63]; ignoring the age needs of laboratory animals [64]; and using single-sex experimental animals [65], it seems to be that they are responsible for blocking these results to achieve clinical implementation. Moreover, study designs were frequently not close to the clinical 
situation, such as reperfusion [66]. Additionally, proteomics analysis of clinical or preclinical intervention strategies, such as Glasgow oxygen level-dependent technology [67] and low oxygen postconditioning [68], may yield more meaningful findings. In addition, a combination of proteomics studies with a real-world study with a follow-up is required [69].

There is no doubt that there is an urgent demand for biomarkers of brain injury after ischemic stroke to maximize benefit from the existing treatment schemes. Therefore, using proteomics as a tool to integrate clinical needs with drug development may be conducive to the discovery of effective biomarkers and their clinical application.

Funding Information This work was supported by grants from the National Natural Science Foundation of China (No. 81830036, $81771255,81771254,81771256)$ and Scientific Department of Jiangsu Province (No. BE2017656)

\section{Compliance with Ethical Standards}

The study was approved by the Ethics Committee of the First Affiliated Hospital of Soochow University. And there is no human or animal subject in this article.

Conflict of Interest The authors declare that they have no conflict of interest.

\section{References}

1. Zhu L, He D, Han L, Cao H. Stroke research in China over the past decade: analysis of NSFC funding. Transl Stroke Res. 2015;6(4): 253-6. https://doi.org/10.1007/s12975-015-0404-z.

2. Waje-Andreassen U, Naess H, Thomassen L, Maroy TH, Mazengia $\mathrm{KY}$, Eide GE, et al. Biomarkers related to carotid intima-media thickness and plaques in long-term survivors of ischemic stroke. Transl Stroke Res. 2015;6(4):276-83. https://doi.org/10.1007/ s12975-015-0403-0.

3. Dykstra-Aiello C, Jickling GC, Ander BP, Zhan X, Liu D, Hull H, et al. Intracerebral hemorrhage and ischemic stroke of different etiologies have distinct alternatively spliced mRNA profiles in the blood: a pilot RNA-seq study. Transl Stroke Res. 2015;6(4):284-9. https://doi.org/10.1007/s12975-015-0407-9.

4. Kim JM, Jung KH, Chu K, Lee ST, Ban J, Moon J, et al. Atherosclerosis-related circulating MicroRNAs as a predictor of stroke recurrence. Transl Stroke Res. 2015;6(3):191-7. https://doi. org/10.1007/s12975-015-0390-1.

5. Lescuyer P, Allard L, Zimmermann-Ivol CG, Burgess JA, HughesFrutiger S, Burkhard PR, et al. Identification of post-mortem cerebrospinal fluid proteins as potential biomarkers of ischemia and neurodegeneration. Proteomics. 2004;4(8):2234-41. https://doi. org/10.1002/pmic.200300822.

6. Allard L, Lescuyer P, Burgess J, Leung KY, Ward M, Walter N, et al. ApoC-I and ApoC-III as potential plasmatic markers to distinguish between ischemic and hemorrhagic stroke. Proteomics. 2004;4(8):2242-51. https://doi.org/10.1002/pmic.200300809.

7. Brea D, Rodriguez-Gonzalez R, Sobrino T, Rodriguez-Yanez M, Blanco M, Castillo J. Proteomic analysis shows differential protein expression in endothelial progenitor cells between healthy subjects and ischemic stroke patients. Neurol Res. 2011;33(10):1057-63. https://doi.org/10.1179/1743132811Y.0000000038.
8. Dayon L, Turck N, Garci-Berrocoso T, Walter N, Burkhard PR, Vilalta A, et al. Brain extracellular fluid protein changes in acute stroke patients. J Proteome Res. 2011;10(3):1043-51. https://doi. org/10.1021/pr101123t.

9. Datta A, Akatsu H, Heese K, Sze SK. Quantitative clinical proteomic study of autopsied human infarcted brain specimens to elucidate the deregulated pathways in ischemic stroke pathology. J Proteome. 2013;91:556-68. https://doi.org/10.1016/j.jprot.2013. 08.017.

10. Garcia-Berrocoso T, Penalba A, Boada C, Giralt D, Cuadrado E, Colome N, et al. From brain to blood: new biomarkers for ischemic stroke prognosis. J Proteome. 2013;94:138-48. https://doi.org/10. 1016/j.jprot.2013.09.005.

11. George PM, Mlynash M, Adams CM, Kuo CJ, Albers GW, Olivot JM. Novel TIA biomarkers identified by mass spectrometry-based proteomics. Int J Stroke. 2015;10(8):1204-11. https://doi.org/10. 1111/ijs.12603.

12. Sharma R, Gowda H, Chavan S, Advani J, Kelkar D, Kumar GS, et al. Proteomic signature of endothelial dysfunction identified in the serum of acute ischemic stroke patients by the iTRAQ-based LC-MS approach. J Proteome Res. 2015;14(6):2466-79. https:// doi.org/10.1021/pr501324n.

13. Nguyen VA, Carey LM, Giummarra L, Faou P, Cooke I, Howells $\mathrm{DW}$, et al. A pathway proteomic profile of ischemic stroke survivors reveals innate immune dysfunction in association with mild symptoms of depression - a pilot study. Front Neurol. 2016;7:85. https://doi.org/10.3389/fneur.2016.00085.

14. Song H, Zhou H, Qu Z, Hou J, Chen W, Cai W, et al. From analysis of ischemic mouse brain proteome to identification of human serum clusterin as a potential biomarker for severity of acute ischemic stroke. Transl Stroke Res. 2018 Nov 21. https://doi.org/10.1007/ s12975-018-0675-2.

15. Munoz R, Santamaria E, Rubio I, Ausin K, Ostolaza A, Labarga A, et al. Mass spectrometry-based proteomic profiling of thrombotic material obtained by endovascular thrombectomy in patients with ischemic stroke. Int J Mol Sci. 2018 Feb 7;19(2). pii: E498. https:// doi.org/10.3390/ijms19020498.

16. Penn AM, Bibok MB, Saly VK, Coutts SB, Lesperance ML, Balshaw RF, et al. Verification of a proteomic biomarker panel to diagnose minor stroke and transient ischaemic attack: phase 1 of SpecTRA, a large scale translational study. Biomarkers. 2018;23(4):392-405. https://doi.org/10.1080/1354750X.2018. 1434681 .

17. Garcia-Berrocoso T, Llombart V, Colas-Campas L, Hainard A, Licker V, Penalba A, et al. Single cell immuno-laser microdissection coupled to label-free proteomics to reveal the proteotypes of human brain cells after ischemia. Mol Cell Proteomics. 2018;17(1): 175-89. https://doi.org/10.1074/mcp.RA117.000419.

18. Chen A, Liao WP, Lu Q, Wong WS, Wong PT. Upregulation of dihydropyrimidinase-related protein 2 , spectrin alpha II chain, heat shock cognate protein 70 pseudogene 1 and tropomodulin 2 after focal cerebral ischemia in rats-a proteomics approach. Neurochem Int. 2007;50(7-8):1078-86. https://doi.org/10.1016/j.neuint.2006. 11.008 .

19. Koh PO. Proteomic analysis of focal cerebral ischemic injury in male rats. J Vet Med Sci. 2010;72(2):181-5. https://doi.org/10. 1292/jvms.09-0364.

20. Ottens AK, Bustamante L, Golden EC, Yao C, Hayes RL, Wang KK, et al. Neuroproteomics: a biochemical means to discriminate the extent and modality of brain injury. J Neurotrauma. 2010;27(10):1837-52. https://doi.org/10.1089/neu.2010.1374.

21. Sung JH, Shah FA, Gim SA, Koh PO. Identification of proteins in hyperglycemia and stroke animal models. J Surg Res. 2016;200(1): 365-73. https://doi.org/10.1016/j.jss.2015.07.020.

22. Xiong X, Liang Q, Chen J, Fan R, Cheng T. Proteomics profiling of pituitary, adrenal gland, and splenic lymphocytes in rats with 
middle cerebral artery occlusion. Biosci Biotechnol Biochem. 2009;73(3):657-64. https://doi.org/10.1271/bbb.80717.

23. Van Elzen R, Ghesquiere B, Timmerman E, Vandamme S, Moens $\mathrm{L}$, Gevaert K, et al. Integrated proteomic analysis reveals a substantial enrichment of protein trafficking processes in hippocampus tissue after hypoxic stress. J Proteome Res. 2010;9(1):204-15. https://doi.org/10.1021/pr900517m.

24. Chen R, Vendrell I, Chen CP, Cash D, O'Toole KG, Williams SA, et al. Proteomic analysis of rat plasma following transient focal cerebral ischemia. Biomark Med. 2011;5(6):837-46. https://doi. org/10.2217/bmm.11.89.

25. Harada S, Matsuura W, Takano M, Tokuyama S. Proteomic profiling in the spinal cord and sciatic nerve in a global cerebral ischemiainduced mechanical allodynia mouse model. Biol Pharm Bull. 2016;39(2):230-8. https://doi.org/10.1248/bpb.b15-00647.

26. Kahl A, Blanco I, Jackman K, Baskar J, Milaganur Mohan H, Rodney-Sandy R, et al. Cerebral ischemia induces the aggregation of proteins linked to neurodegenerative diseases. Sci Rep. 2018;8(1):2701. https://doi.org/10.1038/s41598-018-21063-z.

27. Gunton AN, Sanchez-Arias JC, Carmona-Wagner EO, WickiStordeur LE, Swayne LA. Upregulation of inflammatory mediators in the ventricular zone after cortical stroke. Proteomics Clin Appl. 2017 Sep;11(9-10). https://doi.org/10.1002/prca.201600092.

28. Law HC, Szeto SS, Quan Q, Zhao Y, Zhang Z, Krakovska O, et al. Characterization of the molecular mechanisms underlying the chronic phase of stroke in a cynomolgus monkey model of induced cerebral ischemia. J Proteome Res. 2017;16(3):1150-66. https:// doi.org/10.1021/acs.jproteome.6b00651.

29. Pang XM, Zhou X, Su SY, Chen CY, Wei ZX, Tao YF, et al. Identification of serum biomarkers for ischemic penumbra by iTRAQ-based quantitative proteomics analysis. Proteomics Clin Appl. 2019 May 16:e1900009 https://doi.org/10.1002/prca. 201900009.

30. Dhodda VK, Sailor KA, Bowen KK, Vemuganti R. Putative endogenous mediators of preconditioning-induced ischemic tolerance in rat brain identified by genomic and proteomic analysis. J Neurochem. 2004;89(1):73-89. https://doi.org/10.1111/j.14714159.2004.02316.x.

31. Bu X, Zhang N, Yang X, Liu Y, Du J, Liang J, et al. Proteomic analysis of cPKCbetaII-interacting proteins involved in HPCinduced neuroprotection against cerebral ischemia of mice. $\mathrm{J}$ Neurochem. 2011;117(2):346-56. https://doi.org/10.1111/j.14714159.2011.07209.x.

32. Feng S, Li D, Li Y, Yang X, Han S, Li J. Insight into hypoxic preconditioning and ischemic injury through determination of nPKCepsilon-interacting proteins in mouse brain. Neurochem Int. 2013;63(2):69-79. https://doi.org/10.1016/j.neuint.2013.04.011.

33. Zgavc T, Hu TT, Van de Plas B, Vinken M, Ceulemans AG, Hachimi-Idrissi S, et al. Proteomic analysis of global protein expression changes in the endothelin-1 rat model for cerebral ischemia: rescue effect of mild hypothermia. Neurochem Int. 2013;63(5):379-88. https://doi.org/10.1016/j.neuint.2013.07.011.

34. Stevens SL, Liu T, Bahjat FR, Petyuk VA, Schepmoes AA, Sontag $\mathrm{RL}$, et al. Preconditioning in the rhesus macaque induces a proteomic signature following cerebral ischemia that is associated with neuroprotection. Transl Stroke Res. 2018 Oct 19. https://doi.org/10. 1007/s12975-018-0670-7.

35. Otero-Ortega L, Gutierrez-Fernandez M, Ramos-Cejudo J, Rodriguez-Frutos B, Fuentes B, Sobrino T, et al. White matter injury restoration after stem cell administration in subcortical ischemic stroke. Stem Cell Res Ther. 2015;6:121. https://doi.org/10. 1186/s13287-015-0111-4

36. Choi TM, Yun M, Lee JK, Park JT, Park MS, Kim HS. Proteomic analysis of a rat cerebral ischemic injury model after human cerebral endothelial cell transplantation. J Korean Neurosurg Soc. 2016;59(6):544-50. https://doi.org/10.3340/jkns.2016.59.6.544.
37. Sung JH, Cho EH, Cho JH, Won CK, Kim MO, Koh PO. Identification of proteins regulated by ferulic acid in a middle cerebral artery occlusion animal model-a proteomics approach. J Vet Med Sci. 2012;74(11):1401-7. https://doi.org/10.1292/jvms.120063.

38. Koh PO. Ferulic acid attenuates the injury-induced decrease of protein phosphatase $2 \mathrm{~A}$ subunit $\mathrm{B}$ in ischemic brain injury. PLoS One. 2013;8(1):e54217. https://doi.org/10.1371/journal.pone. 0054217.

39. Koh PO. Ferulic acid prevents cerebral ischemic injury-induced reduction of hippocalcin expression. Synapse. 2013;67(7):390-8. https://doi.org/10.1002/syn.21649.

40. Sung JH, Gim SA, Koh PO. Ferulic acid attenuates the cerebral ischemic injury-induced decrease in peroxiredoxin-2 and thioredoxin expression. Neurosci Lett. 2014;566:88-92. https:/ doi.org/10.1016/j.neulet.2014.02.040.

41. Merali Z, Gao MM, Bowes T, Chen J, Evans K, Kassner A. Neuroproteome changes after ischemia/reperfusion injury and tissue plasminogen activator administration in rats: a quantitative iTRAQ proteomics study. PLoS One. 2014;9(5):e98706. https:// doi.org/10.1371/journal.pone.0098706.

42. Zhang Z, Wu R, Li P, Liu F, Zhang W, Zhang P, et al. Baicalin administration is effective in positive regulation of twenty-four ischemia/reperfusion-related proteins identified by a proteomic study. Neurochem Int. 2009;54(8):488-96. https://doi.org/10. 1016/j.neuint.2009.02.005.

43. Koh PO. Identification of proteins differentially expressed in cerebral cortexes of Ginkgo biloba extract (EGb761)-treated rats in a middle cerebral artery occlusion model-a proteomics approach. Am J Chin Med. 2011;39(2):315-24. https://doi.org/10.1142/ S0192415X11008841.

44. Shah FA, Gim SA, Sung JH, Jeon SJ, Kim MO, Koh PO. Identification of proteins regulated by curcumin in cerebral ischemia. J Surg Res. 2016;201(1):141-8. https://doi.org/10.1016/j.jss. 2015.10.025.

45. Cui Y, Liu X, Li X, Yang H. In-depth proteomic analysis of the hippocampus in a rat model after cerebral Ischaemic injury and repair by Danhong injection (DHI). Int J Mol Sci. 2017 Jun 24;18(7). pii: E1355 https://doi.org/10.3390/ijms18071355.

46. Shah FA, Park DJ, Koh PO. Identification of proteins differentially expressed by quercetin treatment in a middle cerebral artery occlusion model: a proteomics approach. Neurochem Res. 2018;43(8): 1608-23. https://doi.org/10.1007/s11064-018-2576-x.

47. Lin X, Liu T, Li P, He Z, Zhong Y, Cui H, et al. iTRAQ-based proteomics analysis reveals the effect of rhubarb in rats with ischemic stroke. Biomed Res Int. 2018;2018:6920213. https://doi.org/ $10.1155 / 2018 / 6920213$

48. Xu H, Liu T, Wang W, Su N, Yang L, Yang Z, et al. Proteomic analysis of hydroxysafflor yellow a against cerebral ischemia/ reperfusion injury in rats. Rejuvenation Res. 2019 Mar 19. https:// doi.org/10.1089/rej.2018.2145.

49. Wang YH, Yang YL, Cheng X, Zhang J, Li W, Du GH. Xiao-XuMing decoction extract regulates differentially expressed proteins in the hippocampus after chronic cerebral hypoperfusion. Neural Regen Res. 2019;14(3):470-9. https://doi.org/10.4103/1673-5374. 245471.

50. Wang X, Zhu C, Wang X, Gerwien JG, Schrattenholz A, Sandberg $\mathrm{M}$, et al. The nonerythropoietic asialoerythropoietin protects against neonatal hypoxia-ischemia as potently as erythropoietin. J Neurochem. 2004;91(4):900-10. https://doi.org/10.1111/j.14714159.2004.02769.x.

51. Sung JH, Cho EH, Kim MO, Koh PO. Identification of proteins differentially expressed by melatonin treatment in cerebral ischemic injury-a proteomics approach. J Pineal Res. 2009;46(3):300-6. https://doi.org/10.1111/j.1600-079X.2008.00661.x. 
52. Sung JH, Cho EH, Min W, Kim MJ, Kim MO, Jung EJ, et al. Identification of proteins regulated by estradiol in focal cerebral ischemic injury-a proteomics approach. Neurosci Lett. 2010;477(2):66-71. https://doi.org/10.1016/j.neulet.2010.04.028.

53. Hori M, Nakamachi T, Rakwal R, Shibato J, Ogawa T, Aiuchi T, et al. Transcriptomics and proteomics analyses of the PACAP38 influenced ischemic brain in permanent middle cerebral artery occlusion model mice. J Neuroinflammation. 2012;9:256. https://doi. org/10.1186/1742-2094-9-256.

54. Ruan L, Huang HS, Jin WX, Chen HM, Li XJ, Gong QJ. Tetrandrine attenuated cerebral ischemia/reperfusion injury and induced differential proteomic changes in a MCAO mice model using 2-D DIGE. Neurochem Res. 2013;38(9):1871-9. https:// doi.org/10.1007/s11064-013-1093-1.

55. Campos-Martorell M, Salvador N, Monge M, Canals F, GarciaBonilla L, Hernandez-Guillamon M, et al. Brain proteomics identifies potential simvastatin targets in acute phase of stroke in a rat embolic model. J Neurochem. 2014;130(2):301-12. https://doi.org/ 10.1111/jnc. 12719.

56. Shah FA, Gim SA, Kim MO, Koh PO. Proteomic identification of proteins differentially expressed in response to resveratrol treatment in middle cerebral artery occlusion stroke model. J Vet Med Sci. 2014;76(10):1367-74. https://doi.org/10.1292/jvms. 14-0169.

57. Gele P, Vingtdeux V, Potey C, Drobecq H, Ghestem A, Melnyk P, et al. Recovery of brain biomarkers following peroxisome proliferator-activated receptor agonist neuroprotective treatment before ischemic stroke. Proteome Sci. 2014;12:24. https://doi.org/10. 1186/1477-5956-12-24.

58. Zhang Z, Zhang G, Sun Y, Szeto SS, Law HC, Quan Q, et al. Tetramethylpyrazine nitrone, a multifunctional neuroprotective agent for ischemic stroke therapy. Sci Rep. 2016;6:37148. https:// doi.org/10.1038/srep37148.

59. Kadri S, El Ayed M, Cosette P, Jouenne T, Elkhaoui S, Zekri S, et al. Neuroprotective effect of grape seed extract on brain ischemia: a proteomic approach. Metab Brain Dis. 2019;34(3):889-907. https://doi.org/10.1007/s11011-019-00396-2.

60. Teoh J, Boulos S, Chieng J, Knuckey NW, Meloni BP. Erythropoietin increases neuronal NDPKA expression, and NDPKA up-regulation as well as exogenous application protects cortical neurons from in vitro ischemia-related insults. Cell Mol Neurobiol. 2014;34(3):379-92. https://doi.org/10.1007/s10571013-0023-8.

61. Llombart V, Garcia-Berrocoso T, Bech-Serra JJ, Simats A, Bustamante A, Giralt D, et al. Characterization of secretomes from a human blood brain barrier endothelial cells in-vitro model after ischemia by stable isotope labeling with aminoacids in cell culture (SILAC). J Proteome. 2016;133:100-12. https://doi.org/10.1016/j. jprot.2015.12.011.

62. Jiang RH, Wu CJ, Xu XQ, Lu SS, Zu QQ, Zhao LB, et al. Hypoxic conditioned medium derived from bone marrow mesenchymal stromal cells protects against ischemic stroke in rats. J Cell Physiol. 2019;234(2):1354-68. https://doi.org/10.1002/jcp.26931.

63. Cai W, Liu S, Hu M, Sun X, Qiu W, Zheng S, et al. Post-stroke DHA treatment protects against acute ischemic brain injury by skewing macrophage polarity toward the M2 phenotype. Transl Stroke Res. 2018;9(6):669-80. https://doi.org/10.1007/s12975018-0662-7.

64. Sutter EN, Mattlage AE, Bland MD, Cherry-Allen KM, Harrison E, Surkar SM, et al. Remote limb ischemic conditioning and motor learning: evaluation of factors influencing response in older adults. Transl Stroke Res. 2018 Aug 7. https://doi.org/10.1007/ s12975-018-0653-8.

65. Faber JE, Moore SM, Lucitti JL, Aghajanian A, Zhang H. Sex differences in the cerebral collateral circulation. Transl Stroke Res. 2017;8(3):273-83. https://doi.org/10.1007/s12975-0160508-0.

66. Simon R, Meller R, Yang T, Pearson A, Wilson G. Enhancing base excision repair of mitochondrial DNA to reduce ischemic injury following reperfusion. Transl Stroke Res. 2018 Dec 8. https://doi. org/10.1007/s12975-018-0680-5.

67. Deuchar GA, van Kralingen JC, Work LM, Santosh C, Muir KW, McCabe $\mathrm{C}$, et al. Preclinical validation of the therapeutic potential of Glasgow oxygen level dependent (GOLD) technology: a theranostic for acute stroke. Transl Stroke Res. 2018 Nov 30. https://doi.org/10.1007/s12975-018-0679-y.

68. Pietrogrande G, Zalewska K, Zhao Z, Johnson SJ, Nilsson M, Walker FR. Low oxygen post conditioning as an efficient nonpharmacological strategy to promote motor function after stroke. Transl Stroke Res. 2018 Aug 28. https://doi.org/10.1007/s12975018-0656-5.

69. Xu H, Ping Y, Lin H, He P, Li W, Dai H. Antiplatelet strategies and outcomes in patients with noncardioembolic ischemic stroke from a real-world study with a five-year follow-up. Transl Stroke Res. 2017;8(3):228-33. https://doi.org/10.1007/s12975-016-0516-0.

Publisher's Note Springer Nature remains neutral with regard to jurisdictional claims in published maps and institutional affiliations. 